\title{
O discurso biomédico nas capas da revista Saúde
}

\section{The biomedical discourse on the covers of Saúde magazine}

\section{El discurso biomédico en las portadas de la revista Saúde}

Tiago Tavares de Castro Fernandes ${ }^{1, a}$

tiagopes@yahoo.com.br | http://orcid.org/0000-0001-5478-9842

Francisco Romão Ferreira ${ }^{1, b}$

chico.romao@yahoo.com.br | http://orcid.org/0000-0003-4504-3621

Cristiane Marques Seixas ${ }^{1, c}$

cris.marques.seixas@gmail.com | http://orcid.org/0000-0003-2630-9746

Eliane Portes Vargas ${ }^{2, d}$

eliamepvargas@gmail.com | http://orcid.org/0000-0002-0236-3732

\footnotetext{
${ }^{1}$ Universidade do Estado do Rio de Janeiro, Programa de Pós-graduação em Alimentação, Nutrição e Saúde. Rio de Janeiro, RJ, Brasil.

2 Fundação Oswaldo Cruz, Instituto Oswaldo Cruz. Rio de Janeiro, RJ, Brasil.

a Mestrado em Alimentação, Nutrição e Saúde pela Universidade do Estado do Rio de Janeiro.

Doutorado em Ciências pela Fundação Oswaldo Cruz.

c Doutorado em Teoria Psicanalítica pela Universidade Federal do Rio de Janeiro.

d Doutorado em Saúde Coletiva pela Universidade do Estado do Rio de Janeiro.
}

\section{Resumo}

Neste artigo, abordamos sentidos e significados dados à comida presentes na revista Saúde como um fator que interfere no consumo de alimentos. Partimos do pressuposto de haver na sociedade contemporânea uma hegemonia do discurso biomédico, disseminado e naturalizado pelo senso comum, que reproduz os interesses do mercado e influencia as escolhas alimentares. A revista desperta interesse justamente por se enquadrar no vasto rol de publicações populares que versam sobre dieta e saúde. Como parte da metodologia utilizada, selecionamos as publicações desde 2013 até 2016, o que corresponde a 36 revistas e constitui o corpus da análise. Com o objetivo de interpretar os aspectos simbólicos, socialmente construídos e expressos no material selecionado, foram identificadas as características mais marcantes e recorrentes nas capas das edições. Observou-se que a centralidade do discurso científico e biomédico está ligada à ideia de influenciar as práticas alimentares e enfatizar o risco de adoecer.

Palavras-chave: Alimentação; Dieta; Nutrição; Saúde; Discurso. 


\begin{abstract}
In this article we approach senses and meanings referring to food present in the Saúde magazine as a factor that interferes with food consumption. We start from the assumption that in contemporary society there is a hegemony of biomedical discourse, disseminated and naturalized by common sense, which reproduces the interests of the market and influences food choices. The magazine arouses interest precisely because it is one of the leading magazines in the vast list of Brazilian popular publications that deal with diet and health. As one of the methodological procedures used, we selected the publications from 2013 to 2016, corresponding to a analysis corpus composed of 36 magazines. In order to interpret the symbolic aspects, socially constructed and expressed in the selected material, the most striking and recurring characteristics were identified on the covers of the editions. It was observed that influencing eating practices and emphasizing the risk of becoming ill is the centrality of scientific and biomedical discourse.
\end{abstract}

Keywords: Food, Diet, Nutrition; Health; Speech.

\title{
Resumen
}

En este artículo abordamos los sentidos y los significados atribuidos a los alimentos presentes en la revista Saúde como un factor que interfiere en el consumo de alimentos. Partimos del supuesto de que existe una hegemonía en el discurso biomédico en la sociedad contemporánea, difundido y naturalizado por el sentido común, que reproduce los intereses del mercado e influye en las elecciones de alimentos. La revista despierta interés precisamente porque se encuentra en la vasta lista de publicaciones populares brasileñas que se ocupan de la dieta y la salud. Uno de los procedimientos metodológicos utilizados ha sido la selección de las publicaciones de 2013 a 2016, correspondientes a 36 revistas que constituyeron el corpus de análisis. Para interpretar los aspectos simbólicos, socialmente construidos y expresados en el material seleccionado, se identificaron las características más llamativas y recurrentes en las portadas de las ediciones. Ha sido observado que la centralidad del discurso científico y biomédico tiene relación con la idea de influir en las prácticas de alimentación, enfatizando el riesgo de enfermarse.

Palabras clave: Alimentación; Dieta; Nutrición, Salud; Discurso.

Contribuição dos autores:

Concepção e desenho do estudo: Tiago Tavares de Castro Fernandes e Francisco Romão Ferreira. Aquisição, análise ou interpretação dos dados: Tiago Tavares de Castro Fernandes e Francisco Romão Ferreira.

Redação do manuscrito: Tiago Tavares de Castro Fernandes, Francisco Romão Ferreira, Cristiane Marques Seixas e Eliane Portes Vargas. Revisão crítica do conteúdo intelectual: Tiago Tavares de Castro Fernandes, Francisco Romão Ferreira, Cristiane Marques Seixas e Eliane Portes Vargas.

Declaração de conflito de interesses: não há.

Fontes de financiamento: Coordenação de Aperfeiçoamento de Pessoal de Nível Superior (Capes).

Considerações éticas: não há.

Agradecimentos/Contribuições adicionais: não há.

Histórico do artigo: submetido: 03 out. 2019 | aceito: 12 fev. 2019 | publicado: 31 mar. 2020.

Apresentação anterior: não houve.

Licença CC BY-NC atribuição não comercial. Com essa licença é permitido acessar, baixar (download), copiar, imprimir, compartilhar, reutilizar e distribuir os artigos, desde que para uso não comercial e com a citação da fonte, conferindo os devidos créditos de autoria e menção à Reciis. Nesses casos, nenhuma permissão é necessária por parte dos autores ou dos editores. 


\section{Introdução}

Uma rápida visita às bancas de revistas mostra-se suficiente para saltarem aos olhos inúmeras publicações cuja temática é o alimento. Encontram-se fartamente disponíveis desde títulos focados num alimento específico, em uma espécie de dossiê listando seus benefícios, passando por outros que se colocam na linha da valorização das dietas da moda ou da construção social de corpos idealizados. Tendências que, na prática, se mesclam em variados textos da mídia que tratam de alimentos e dietas perfeitas. Entre as vantagens do bem comer e do corpo adequado citam sempre, sem exceção, como bem maior a saúde, vista aqui como uma escolha racional e objetiva. Para o leitor fazer 'as escolhas adequadas' basta ter 'as informações corretas'. Neste modelo construído de comunicação, o sujeito é descrito como livre para escolher, tendo a ideia de uma objetividade científica como norte condutor.

A banca de revista que conhecemos hoje é fruto de um longo processo de transformação da forma como os interesses do mercado se fazem representar junto ao consumidor. Para Mira ${ }^{1}$, o universo editorial se segmentou ao longo do tempo. As revistas da primeira metade do século XX caracterizavam-se por programas mais indiferenciados de defesa dos costumes, das virtudes morais e sociais nos quais os 'conselhos domésticos' se destacavam. No entanto, já continham traços do discurso da ciência. As revistas daquele período cederam lugar a publicações mais especializadas, como se observa na dinâmica da revista Saúde na qual os conteúdos valorizados socialmente se apresentam atualizados.

Neste artigo, trataremos dos sentidos e significados dados à comida que permeiam um determinado tipo de recurso midiático. Trataremos especificamente da revista Saúde, uma publicação mensal da Editora Abril Mídia S.A. Destacaremos como o discurso biomédico hiper valoriza um determinado conceito de saúde que se articula à produção de escolhas alimentares. Partimos do pressuposto de haver, na sociedade contemporânea, uma forte influência da racionalidade nutricional sobre as práticas alimentares que coparticipa da produção de uma subjetividade mediada pelos interesses do mercado.

O discurso biomédico apresentado na revista apresenta visão limitada do processo saúde-doença, produzindo o que Kenneth Camargo Jr. ${ }^{2}$ chama de tirania da "saúde" e, por meio do discurso, uma expansão indefinida, e potencialmente infinita, do conceito de saúde passa a encampar toda a experiência humana. Tal discurso se baseia no estreitamento dos ideais éticos e estéticos de uma "boa vida", reduzida a viver muitos anos com o mínimo de doenças, sem considerações sobre prazer ou aspirações para além do individual, uma saúde "medrosa e restritiva". Um discurso também marcado pela expansão de um mercado de consumo de produtos de "saúde": alimentos funcionais, academias de ginástica, dispositivos de uso doméstico. Nessa perspectiva, "a vida humana passa a ser marcada apenas nesse registro; não se come ou se bebe mais para ter prazer, mas porque determinados alimentos e bebidas protegem contra certas doenças, como se deixa de beber ou comer para evitar os riscos associados a outras tantas bebidas e alimentos; não se faz exercícios pelo prazer da experiência corporal, mas para "se cuidar".

Nesse sentido, a revista desperta interesse justamente por se enquadrar no vasto rol de publicações populares que produzem conteúdo sobre dieta e saúde. Cabe ressaltar que este nicho do mercado editorial é recente e que o número de publicações acerca de usos funcionais dos alimentos aumentou significativamente na última década. Esse discurso vai ao encontro também do que Viana ${ }^{3}$ chama de racionalidade nutricional, entendida aqui como "a influência que práticas alimentares sofrem do suposto estado de supremacia que a ciência detém, a qual sugere em seu discurso a necessidade de saúde. A partir do pressuposto da racionalidade nutricional como dever comer, supõe-se que este participa do processo de medicalização da comida ao descredenciar o sujeito do autocuidado alimentar, engendrar a ideia de risco de suposta alimentação inadequada e fomentar a ideia de que comer bem é comer de acordo com princípios científicos. A disseminação para o grande público de estudos científicos e os resultados de pesquisas relevam o papel da racionalidade nutricional na promoção de 'melhor' saúde em detrimento da existencialidade da comida e de seu papel agregador nas relações intersubjetivas”3. 
O enquadramento da mídia como objeto deste estudo se dá por suposição de que esta se configura como uma espécie de repositório de repertórios argumentativos que repercutem na sociedade atual. O site da revista Saúde além de apresentar algumas matérias da edição que está nas bancas, disponibiliza as capas e índices de todas as edições da revista desde 2014, oferecendo um link para assinatura onde a revista é assim apresentada: "Qualidade de vida pede informação de qualidade. O melhor conteúdo sobre nutrição, medicina e novos tratamentos para quem busca bem-estar"4. Portanto, temos uma autêntica representante do setor de mídia que se ocupa do mercado do "bem-estar", trabalhando no sentido de promover uma mediação entre o grande público e as inovações tecnológicas e últimos lançamentos do mercado médico, nutricional e farmacêutico. Se pensarmos em termos de mercado, estamos falando dos setores da grande mídia, que colaboram com a vasta indústria do comercializável 'bem-estar social'.

As mídias presentes no segmento de revistas se colocam como especialistas no setor e, através da repetição de conceitos, difundem discursos que aderem ao público desfilando suas 'verdades' hegemônicas sobre a saúde e a alimentação. A profusão de 'polêmicas alimentares', tais como as que atualmente são construídas em torno de alimentos como o ovo, o café, ou os açúcares, atende a interesses de mercado, que podem estar relacionados à produção, à comercialização, ou à pesquisa tecnológica voltada para alimentos. Acreditamos que nesse nicho do mercado editorial voltado para os cuidados com a saúde, entre os quais se encontra a mídia dos alimentos, há certos estilos discursivos recorrentes que compõem a retórica da exacerbação do cuidado com a saúde e da comercialização de um ideal de saúde perfeita ${ }^{5}$. De fato, se olharmos para os determinantes sociais da alimentação, observaremos que os modos alimentares estão imbricados com as questões culturais. Por isso, tomamos como pressuposto a observação de Mary Jane Spink e colaboradores ${ }^{6}$, que dizem: "[...] que a mídia tem um papel fundamental na circulação de repertórios utilizados para a produção de sentidos no cotidiano de nossas vidas, por ser onipresente no mundo contemporâneo e por conferir uma visibilidade sem precedente aos acontecimentos (incluindo aí as novas informações e descobertas) que leva a uma reconfiguração das fronteiras entre o espaço público e privado e produz novas formas de comunicação e interação".

Na presente reflexão, trazemos uma breve caracterização do perfil da revista Saúde com relação ao estilo da publicação e ao modo por meio do qual ela oferece aos leitores conteúdos identificados como 'saúde'. Lançando mão de alguns referenciais teóricos relativos ao discurso científico e biomédico vinculados ao ato de comer, discutimos a centralidade do processo de farmacologização ${ }^{2}$ nas mensagens difundidas sobre comida e práticas alimentares, apontando existir uma determinada concepção de saúde que enfatiza o risco de adoecer.

Podemos entender a farmacologização como a tradução ou transformação de condições, capacidades e potencialidades humanas em oportunidades para intervenções farmacológicas mesmo sem haver um diagnóstico médico específico, tornando cada vez maior a utilização de medicamentos sem indicação terapêutica, com a finalidade de atingir uma certa 'supernormalidade' ao consumir determinados alimentos. Chama a atenção a aproximação entre as indústrias farmacêuticas, de alimentos e editorial por meio da publicidade de alimentos e, consequentemente, a naturalização dos processos de medicalização da comida. Ainda, segundo Camargo Jr. ${ }^{2}$ : "A farmacologização cria identidades em torno do uso de determinados fármacos, além de reforçar a ideia de que 'para cada mal há um comprimido', levando à expansão do mercado farmacêutico para além das áreas tradicionais, incluindo o uso por indivíduos saudáveis, ao enfraquecimento da predominância da profissão médica criando relações diretas da indústria com 'consumidores' e a colonização da vida humana pelos produtos farmacêuticos". 


\section{A revista Saúde: o material e seu contexto}

Ao observarmos as bancas de revistas, podemos notar a grande segmentação deste mercado editorial, que se mostra cada vez mais especializado. Frente à grande diversidade de publicações, temos um verdadeiro painel de títulos que se ocupam estritamente de assuntos relativos à saúde, à alimentação e à forma física, ou aos três aspectos materializados em uma só publicação como no caso da revista Saúde. Tendo por objetivo interpretar os aspectos simbólicos, socialmente construídos e presentes nos conteúdos circulantes dessa revista foram identificados traços recorrentes de medicalização e famarcologização em um conjunto característico do material em tela: os conteúdos das capas. Cabe destacar, no entanto, a presença desses traços de modo muito naturalizado no conjunto das edições da revista.

Nossa pesquisa se deteve mais atentamente à análise das capas, mas apenas a título de ilustração, quando observamos o índice remissivo, por exemplo, ele se assemelha a um catálogo de doenças. As doenças crônicas associadas a determinados tipos de grupos sociais são as mais recorrentes: hipertensão arterial, câncer, diabetes e problemas cardíacos, listados eventualmente como comorbidades, associam-se à obesidade, o 'pior dos males' descrito a partir da crítica ao estilo de vida sedentário e a uma dieta desequilibrada observável em pessoas descritas como portadoras de baixa autoestima e, consequentemente, dotadas de uma vontade fraca. Revela, assim, um preconceito com pessoas com o corpo considerado gordo, e uma moralização dos discursos que configuram a lipofobia contemporânea, transformando um problema clínico e coletivo em uma deficiência ou defeito moral individual.

A título de contextualização, lançando um olhar para o mercado editorial de jornais e revistas, pode-se dizer que a Abril Mídia S/A representou a maior potência editorial no mercado brasileiro de publicações durante o século XX e início do século XXI, quando ainda não havíamos testemunhado o crescimento vertiginoso das mídias digitais que levaria a uma revolução na comunicação de massa. O ano 2015 marcou 65 anos de existência do grupo Abril, cujos trabalhos editoriais foram iniciados na década de 1950, lançando o primeiro exemplar da revista do 'Pato Donald' no Brasil. Precisamente no meio dessa trajetória, há 33 anos, a editora Abril fez o lançamento do título que nos propomos a estudar, a revista Saúde. Naquela época, a revista ingressou no mercado voltada para o segmento de saúde na 'terceira idade' ou publicando matérias sobre a 'maturidade'. Apesar de ter o mesmo nome e ser da mesma empresa, a revista era outra e surgia num Brasil que também vivia outro momento político e econômico.

A revista Saúde foi intencionalmente escolhida, portanto, como um veículo passível de observação da circulação de conteúdos mediadores na produção de sentidos e discursos sobre o corpo, a saúde e as formas de lidar com a alimentação. O próprio site da editora fornece material de divulgação das publicações da revista, o que, para os analistas do discurso ${ }^{7,8}$, pode ser tomado como leitura complementar que ajuda o entendimento do contexto editorial.

As questões problematizadas a partir da revista Saúde se articulam a reflexões que envolvem diferentes campos, como alimentação, nutrição, cultura, informação e mídia, saúde e ciência uma vez que tais campos de produção do saber engendram a produção de uma subjetividade mediada pelos interesses do mercado. A metodologia utilizada visando à análise do material comportou o acesso a todas as revistas publicadas entre setembro de 2013 e maio de 2016, compondo o corpus do estudo um total de 36 revistas. Deste total, o presente trabalho coloca ênfase nos aspectos simbólicos, socialmente construídos, presentes nos conteúdos das capas da revista Saúde, em que predomina o discurso de risco ligado à perspectiva biomédica relacionada ao corpo e à alimentação de modo muito significativo.

Partimos do pressuposto de que os discursos proferidos na revista não são neutros, espontâneos ou aleatórios, sem finalidade ou intencionalidade, pelo contrário. Segundo Michel Foucault 7 , o discurso científico de um agente participante de um determinado campo não resulta apenas de um desejo de produção, divulgação ou atualização de um saber. Esse discurso necessariamente se articula em torno dos 
conflitos, das tensões e da dinâmica existente no interior do meio científico em que ele está inserido e se manifesta como uma forma de dissimular o que é dito pessoalmente, invocando um ausente que se faz presente e mostra sua força. O valor da autoridade está em ocultar-se atrás de um terceiro, de modo a sugerir o que pensa sem necessitar responsabilizar-se por isso. Trata-se de um falar ambíguo no qual o locutor se define ao mesmo tempo como autoridade e como o representante de uma autoridade que não está ali. O discurso da ciência traz implícito o peso da tradição construída a partir da ciência ocidental moderna e sua aura de confiabilidade e compromisso com a verdade. ${ }^{7}$

Nesse sentido, qualquer coisa que venha a ser dita, que seja pensada, esquadrinhada, modificada e construída de modo a tentar dizer a palavra certa, o argumento certo, a palavra que convém, o discurso que funcione e que não traga problemas. Para isso, as estratégias se rearticulam, (re)utilizam conceitos, ideias ou sentidos proferidos no passado, mas que possam se 'atualizar' no discurso atual. O discurso é sempre atualizado sem alterar o seu 'núcleo duro', suas verdades primeiras. É sempre mais do mesmo, variações sobre o mesmo tema, fazendo com que a fala científica se metamorfoseie em argumentações que remetem sempre às mesmas questões, a partir da mesma abordagem, construída a partir da mesma perspectiva, e obviamente, chegando às mesmas respostas7. Os discursos proferidos na revista, portanto, são estratégias de dissimulação, disseminação e naturalização de um tipo de discurso específico, mas com ares de neutralidade, criando uma aproximação com o senso comum, mas reforçando nas entrelinhas a ideia de uma verdade científica que legitima as falas.

Nossa escolha metodológica privilegiou as capas e, nelas, encontramos um padrão que reforça a discursividade sobre a alimentação funcional (consumo de alimento com a intenção de se absorver substâncias apontadas como melhoradoras da saúde do corpo) é a tônica de seu vocabulário, bem como a ideia de que cada dieta dispõe de uma meta corporal para o seu praticante. Nesta direção, salvo raras edições (seis edições do total de 36), as capas têm corpos, ou parte de corpos femininos, e são compostas basicamente por uma foto de um alimento impresso em cores vibrantes em tamanho grande e disposição central. Projetada sobre um fundo claro, a logomarca com o nome da revista, sempre apresenta uma cor que se relaciona com a coloração do alimento em destaque na reportagem de capa. Só de fitar a capa, é possível que o leitor já se depare com alguma sentença que assuma o estatuto de regra alimentar, a exemplo das sentenças e enunciados: "Mais fruta e menos suco" (jan/2014) ${ }^{4}$ ou " 5 vegetais por dia - Essa porção reduz em $25 \%$ a chance de você ter qualquer doença” (out/2014) ${ }^{4}$. É possível também que o leitor saiba mais sobre uma inovação científica como, por exemplo, sobre a nova dieta anticâncer, ou aprenda que deve comer queijo para o 'bem do coração' ou, ainda, comer frutas vermelhas para o 'bem da cabeça' com sugestiva associação entre os efeitos da ingesta de alimentos e a sua funcionalidade para os órgãos do corpo. A título de ilustração, podemos citar algumas capas que mencionam os alimentos e suas respectivas funcionalidades: (Set/ 2013) Cereal Matinal - Colesterol, controle de peso, turbina o raciocínio; (Out/2013) Feijão - Câncer; (Nov/2013) Abacate - Coração; (Dez/2013) Iogurte - Afina a cintura; (Jan/2014) Abacaxi - O suco eleva a glicemia muito mais rápido que a fatia da fruta; (Mai/2014) Sardinha - Turbina a saúde; (Jun/2014) Frutas Vermelhas - Freia o envelhecimento do cérebro; (Jul/2014) Brócolis - Ativa genes que suprimem tumores; (Set/2014) Manteiga e Açúcar - A manteiga não é tão ruim assim e o açúcar é um perigo para o coração; (Out/2014) Cinco vegetais - Reduzem a chance de ter doença; (Dez/2014) Queijo - Controla peso, pressão e colesterol.

A questão do risco relacionado ao corpo e à alimentação é muito presente na revista. Observamos, por vezes, que a noção de risco se associa a palavras como 'gordura', 'aumento de peso', ou 'calorias". Isso caracteriza traços explícitos de 'lipofobia', entendida aqui como um preconceito ou aversão à gordura, que denota um cenário onde o ideal de saúde está diretamente ligado ao imperativo estético. A gordura, do alimento ou do corpo, é proibida no primeiro caso, e vista apenas como um 'objeto carreador de nutrientes' no segundo. A questão do risco também vem sendo retratada nas capas da revista Saúde. Em sua 
diagramação atual, além da ilustração principal e da manchete da reportagem de capa escrita com fontes de letras grandes, tem mais cinco chamadas menores, justapostas, costumeiramente na parte inferior da capa. Esses textos são curtos, bem diretos e, geralmente, repercutem nas práticas alimentares ou práticas de boa saúde.

Outra característica da revista, que também merece um olhar atento, é o recorrente discurso de autoajuda das publicações. Para Salem ${ }^{8}$, tal literatura expressa uma lógica cultural que a ultrapassa largamente. Os livros desse gênero se dispõem a oferecer um conjunto detalhado de receitas e exercícios que garantem que qualquer um pode 'tornar-se outra pessoa' (como descrito nos manuais de autoajuda), fornecendo de modo simples e prático a cura para males físicos e mentais, e o caminho para conquistar o sucesso no trabalho e na vida afetiva assim como a felicidade. Acreditamos que o mesmo se aplica a esse segmento do mercado de revistas, por se configurar como meio de direcionamento do estilo de vida dos consumidores em potencial.

\section{Conceitos e perspectivas que fundamentam o olhar sobre a revista}

O campo da alimentação e nutrição é, grosso modo, um campo que se funda sobre uma condição: a necessidade fisiológica do alimentar-se ${ }^{9}$. Mas, no tipo de sociedade em que vivemos, as necessidades básicas individuais e coletivas são capturadas pela lógica do consumo. Um dos traços da sociedade contemporânea relacionado a esse sistema é o fetiche da mercadoria, ou seja, dos produtos comerciais a exemplo dos produtos de gênero alimentício ${ }^{10}$. A construção dos discursos nas capas da revista Saúde reforça a ideia de que o consumo de alimentos deixa de ser uma necessidade biológica e se transforma em um código de distinção e inclusão no mundo social, tornando-se um processo de objetivação do sujeito social, cuja identidade e posição na hierarquia social se dão a partir de objetos de consumo. Torna-se sujeito pelos objetos, pois são eles que mobilizam os códigos de pertencimento a determinados grupos (na medida em que você é o que você come, com quem come, com que frequência e em qual local come); fazendo com que indivíduos se construam como sujeitos sociais pelo consumo, o que você come lhe dá um 'lugar social' e você é o que você consome. O consumo está no coração desse duplo processo de cooperação e de competição material, de inclusão e de exclusão social, de construção e de diferenciação identitária e simbólica. Se a fome é uma necessidade biológica, comer de forma saudável, transformando o alimento em medicamento e segundo os preceitos da racionalidade nutricional de modo a construir o corpo ideal, torna-se um modo de vida.

Os aspectos culturais que envolvem as práticas alimentares permeiam diferentes campos do conhecimento, resultando em diferentes modos explicativos por meio dos quais os alimentos são simbolizados e, consequentemente, valorados. Nessa perspectiva, o alimento transformado em comida tem suas funções e seus significados inacessíveis exclusivamente pelas leituras biológicas ou afins ${ }^{11}$. Para acessálo, é preciso levar em conta os aspectos simbólicos presentes nas práticas alimentares, uma vez que uma simples refeição incorpora os códigos e símbolos do jogo social cujas relações são mediadas pelo mercado. $\mathrm{O}$ alimento não é um artefato da natureza, ele é transformado pelo jogo simbólico da cultura ${ }^{12} \mathrm{e}$, portanto, está imerso nas práticas cotidianas de consumo alimentar. Contudo, mesmo considerando que o sentido atribuído ao alimento se constrói no espaço simbólico do cotidiano, o discurso científico e biomédico é o contexto que favorece a atribuição de um valor de verdade aos conteúdos da revista Saúde.

No universo simbólico da cultura contemporânea. há um conjunto de representações relativas aos valores dominantes na sociedade, como o individualismo (a compreensão dos sujeitos como unidades pontuais autônomas), a competição entre os indivíduos como regra básica de relacionar-se, o consumismo, entendendo por individualismo a disposição dos indivíduos como objetivo do viver, o cuidado com o corpo como unidade central (e muitas vezes única) delimitadora do indivíduo com relação aos outros, bem como as estratégias de valorização deste corpo para obter, a partir dele, dinheiro, status e poder. 
Essas representações e estratégias permeiam os sentidos atribuídos às práticas de saúde, substituindo-as e dirigindo-as no sentido da ratificação e do fortalecimento dos valores centrais da sociedade já mencionados.

Como mencionamos anteriormente, o discurso da ciência (racionalidade científica) traz implícito o peso da tradição construída a partir da ciência ocidental moderna e sua aura de confiabilidade e compromisso com a verdade. Não basta dizer a verdade, é preciso dizê-la a partir do discurso que é considerado verdadeiro. O verdadeiro só existe obedecendo a regras de uma "polícia discursiva", ativada a cada discurso. O discurso biomédico, como um discurso que se baseia em evidências científicas, se apresenta como o discurso hegemônico dentro do campo da alimentação, nutrição e saúde, representando uma força gravitacional na qual orbitam séries de outros discursos, tecnologias e práticas em saúde que, por sua vez, produzem outras séries de discursos, ideologicamente compartilhados.

Para Miguelote e outros ${ }^{14}$, o conhecimento científico se configura também como uma espécie de mercadoria, transformando-se em moeda de troca num mercado complexo e sofisticado. Sobre a produção e difusão do conhecimento biomédico é possível utilizar a expressão indústria do conhecimento para definir os processos de negociação da produção científica que envolvem a construção do conhecimento médico e a produção de artigos científicos. Os autores defendem que, embora o discurso da indústria farmacêutica, por exemplo, anuncie colaboração na produção de conhecimento médico, essa colaboração não está comprometida com a saúde pública. A indústria do conhecimento funciona como um aparato tecnocrático que implica aspectos éticos, transformando "o processo de legitimação científica em estratégia de marketing, compromete a credibilidade do processo de construção de conhecimento médico e incentiva distorções nos critérios de avaliação de qualidade dos artigos científicos" ${ }^{\prime 13}$. O conceito de indústria do conhecimento é identificado como parte integrante de um complexo médico industrial, que, segundo Cordeiro e Gadelha ${ }^{14,15}$, envolve a formação profissional, as indústrias e a prestação de serviços médicos, e focaliza o processo de produção e de consumo de medicamentos.

Cabe destacar que a biomedicina se baseia na racionalidade da mecânica clássica, surgida no pensamento moderno, atualizando a noção de um mecanismo que possuiria uma validade universal e possibilitaria a criação de um modelo baseado em leis de aplicação geral, não se ocupando de casos individuais. O caráter generalizante deste modelo naturaliza a noção de uma máquina universal que daria conta da complexidade humana, subordinando o que é desta ordem a princípios de causalidade linear de caráter mecanicista. Esta abordagem teórica e experimental pressupõe o isolamento de partes, tendo como pressuposto que o funcionamento do todo é necessariamente dado pela soma das partes ${ }^{16}$. O que a revista faz em termos de seu conteúdo é atualizar, a cada número, o poder biomédico de determinar o que é verdadeiro e "apresentar de maneira simples e fácil"16 para o leitor, conhecimentos médico-científicos considerados complexos.

A instituição médica, como detentora hegemônica de um saber sobre o corpo, se encontra socialmente legitimada a proferir um discurso da verdade sobre a saúde, que se materializa tanto na revista quanto nas práticas sociais de promoção da saúde. Isto se dá por meio de intervenções sobre a produção das 'melhores escolhas' alimentares, racionalizadas e/ou higienizadas, tendo por esteio o discurso científico de uma racionalidade nutricional. Nesse contexto, o papel da mídia e do mercado apresentam-se estratégicos como veículos dos discursos oriundos do aparato médico-farmacêutico e nutricional.

Na revista Saúde, o discurso científico-nutricional define as formas de ação e cria representações do alimento a partir de sistemas de exclusão, classificação e ordenação dos mesmos. Tais discursos se apresentam para o senso comum como verdades, formas estruturantes ou sistemas de saber. Criam, por conseguinte, valores simbólicos que são reproduzidos cotidianamente. Nessa produção cotidiana de sentidos, a revista apresenta o discurso autorizado dos especialistas, geralmente nutricionistas, como estratégia para que a revista ganhe peso e respeitabilidade junto ao seu público. As matérias, portanto, são sempre ligadas a instituições de pesquisa com reconhecimento internacional. Deste modo, o discurso é sempre atualizado sem alterar a sua lógica, suas verdades primeiras. As modulaçãoes dicursivas reproduzem 
"certezas científicas" ainda que essas mesmas verdades mudem de tempos em tempos, pois o saber científico muda e com ele suas "certezas". O valor da autoridade que a ciência imprime na revista está em ocultar-se em um processo de legitimação do conhecimento científico, de modo a sugerir o que pensa sem necessitar responsabilizar-se por isso.

Os processos de legitimação do conhecimento científico articulam-se ao fenômeno da medicalização, assim como a um outro processo que escapa da conceituação estrita da medicalização e que é a farmacologização ${ }^{2}$. O termo medicalização, de acordo com a conceituação feita por Conrad $^{17}$, consiste em um processo no qual problemas anteriormente não considerados estritamente 'médicos', ou relacionados à saúde, são transformados em problemas médicos que se apresentam como transtornos ou doenças. A farmacologização $0^{18}$, por sua vez, consiste na transformação das condições e potenciais humanos em oportunidades para as intervenções farmacológicas.

A articulação dos processos acima descritos, no âmbito não só da ciência mas também do senso comum, nos possibilita pensar na penetração de uma racionalidade nutricional ${ }^{3}$ no complexo médico industrial e na própria indústria do conhecimento mencionada anteriormente. Dessa forma, podemos propor a existência no campo da alimentação e nutrição de um complexo médico/alimentar industrial, entendido como o conjunto do mercado de alimentos e bebidas, da cadeia produtiva da indústria alimentar em anexo à rede de distribuição, permeados por uma crescente medicalização e pela farmacologização da comida, assim como de toda a produção discursiva correlata a esses processos.

\section{Os discursos da saúde sobre o risco de adoecer e suas estratégias}

A análise das estratégias discursivas expostas nos meios de comunicação visa compreender os sentidos e significados das reportagens e anúncios publicitários. Quais são as origens de tais discursos? Quais interesses são representados ali? Sabemos que a revista não cria ou inventa um universo próprio, nem constrói sentidos que são reproduzidos pela sociedade. Ao contrário, ela se apropria de sentidos e significados que estão na sociedade e são naturalizados no cotidiano como 'verdades ou certezas científicas', como já indicamos anteriormente. O discurso da ciência ou dos especialistas é utilizado para legitimar os discursos e interesses dos anunciantes e da linha editorial da revista.

Revistas como a Saúde são veículos de comunicação de grande abrangência. Os discursos proferidos nas suas versões, impressa e virtual, carregam não apenas a legitimidade da marca Abril Mídia S.A, como também reforçam e articulam discursos do campo biomédico, dos especialistas, das empresas que anunciam, mas sempre tendo como pano de fundo um suposto saber cientificamente comprovado que se transforma em produto ou norma a ser seguida. Existe, portanto, uma produção de sentidos nesses meios de comunicação que recaem sobre a alimentação. São produzidos por setores das ciências da saúde e encontram aderência nos sujeitos que habitam os espaços urbanos contemporâneos. Tais discursos encontram respaldo no senso comum e são discursos convincentes, potentes, pois são chancelados e legitimados pelo saber biomédico. Sempre nos deparamos com aquela sensação implícita de que ‘o profissional da saúde recomenda'.

A alimentação, nessa direção, vai muito além de sua acepção biológica, passível de compreensão apenas em acordo com descritores e construtos biomédicos. Pesquisar 'Comida' contemporaneamente é receber um convite a realizar olhares interdisciplinares, já que esta se encontra recoberta por camadas de produções simbólicas que se mesclam e se hibridizam construindo imbricações epistêmicas. Nesta perspectiva, analisar a comida em sua dimensão simbólica permite perceber nas entrelinhas como a indústria de alimentos e a ciência da nutrição produzem sentidos, valores e juízos sobre o comer. "A biomedicina, em suas pesquisas, se apropria do 'alimento', compreendendo-o como elemento da ordem da natureza associado a uma concepção de corpo orgânico funcional e objeto de modificações nesse corpo. As Ciências Sociais têm a "comida" como elemento da ordem da cultura associada a uma concepção de corpo social em que ela é expressão de uma forma de organização social"12. 
A comida como produto da cultura está condicionada a uma série de discursos, sentidos e significados, carregados de subjetividade e memórias que traduzem a história de um povo. Mas o alimento incorpora também interesses econômicos, políticos e culturais e não pode ser visto apenas como um composto bioquímico com nutrientes ou transformado em mero produto de consumo ou medicamento com propriedades terapêuticas. Portanto, a comida não contém somente nutrientes, valores energéticos ou calóricos por grama, ela também abriga inscrições simbólicas variadas que expressam valores sociais capazes de distinguir os seus habituais consumidores, que se agrupam em torno de signos produzidos nos meios científicos e propagados de acordo com o interesse da mídia, de acordo com o que se pode depurar do trabalho com a revista.

Ao incorporar o conceito de risco, o conceito de saúde se destaca e incentiva a cultura do medo, apresentando um cardápio de medidas preventivas no qual a alimentação ocupa um lugar de destaque no hábito saudável: alimentos são prescritos, dosagens são recomendadas e excessos são recriminados. Atualmente, uma série de trabalhos produzidos nas mais diversas áreas da saúde, leva em conta fatores de risco e vulnerabilidade de grupos, indivíduos ou células, que às vezes servem de substrato para a elaboração de escalas e instrumentos para medir e delimitar noções diagnósticas. Mas como o conceito de risco impacta o universo alimentar?

O alimento, da mesma forma, é tratado como algo utilitário e funcional, sob uma metáfora de combustível que alimenta a máquina, sua função é apenas melhorar o desempenho e a funcionalidade, melhorar o funcionamento da engrenagem e 'turbinar' a 'performance' humana. A saúde é vista na perspectiva da medicina estética, do consumo (de medicamentos e serviços) e do mercado. Ela é tratada como o meio de manter-se 'saudável', ativo e produtivo para o mercado. O leitor, geralmente leigo, não percebe o jogo discursivo e os interesses corporativos e institucionais presentes nas matérias, nos anúncios e nas entrelinhas do texto da revista Saúde.

A revista constrói e reproduz uma espécie de paranoia pelo saudável, uma mania de consumir saúde, pois, apesar da ideia de saúde ser vendida como tema principal, a revista se dedica às doenças, aos alimentos que supostamente previnem ou curam doenças, aos últimos tratamentos e descobertas sobre doenças, principalmente às doenças crônicas como diabetes e câncer. Basta uma comparação entre o índice remissivo da publicação ao longo de um ano para entender que a lógica editorial tem como tônica a linguagem do risco que se alimenta da culpabilização do indivíduo ${ }^{6}$.

Risco em epidemiologia faz menção à probabilidade de ocorrência de um evento (mórbido ou fatal), mas também funciona como um termo não técnico que inclui variações probabilísticas quanto a desfechos desfavoráveis. Segundo conclui Castiel ${ }^{19}$, a própria ideia de probabilidade pode ser entendida de dois modos distintos: de forma subjetiva, intuitiva, crente, isto é, como incerteza que não se consegue medir, ou de maneira objetiva, racionalizada, mensurável mediante técnicas probabilísticas, como incerteza capaz de ser medida. Pautada nas tais técnicas probabilísticas, a "abordagem dos fatores de Risco" ou "Marcadores" visam

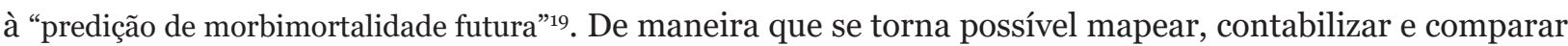
indivíduos, em relação a exposições aos fatores de risco e propor intervenções preventivas.

É interessante notar que o risco é, no imaginário da revista, imputado a modos de viver (alimentação, sono, sexo, comportamentos diários em geral) que já foram vividos, o risco recai sobre as práticas já executadas. Ou, se olharmos para a história do indivíduo, a conta do risco funciona numa perspectiva retroativa, pela qual o alimento que é associado a um determinado risco, hoje, faz parte da alimentação da pessoa por toda uma vida, e traz à cena a noção de culpa. Eis que surge o 'especialista' ou expert que, de acordo com suas recentes descobertas da última semana, faz enquadrar práticas, já assentadas como expressões culturais de um povo, como atitudes perigosas, recrimináveis, danosas para a saúde. A noção de risco instaura uma dinâmica de culpabilização do sujeito, posto que, a partir das informações disponibilizadas, o cuidado de si 
torna-se uma escolha saudável, uma vez que não se cuidar é assumir o ônus da doença e a responsabilidade por ela.

O fenômeno que mais frequenta o imaginário presente na revista Saúde nesse caso, de acordo ainda com o pensamento de Camargo Jr. ${ }^{2}$, é a farmacologização. Expressa por meio da ênfase na suplementação alimentar, mas não exclusivamente, também remete à farmacologização do alimento. Aqui vemos, em relação aos alimentos o que, no caso, seria a atribuição de um valor farmacêutico a eles, transformando-os em medicamentos. Desse dispositivo a revista é farta. Como podemos observar nos exemplos recortados da revista Saúde(jun/2015)4: "gengibre para os diabéticos: como usá-lo para baixar a glicose" ou "iogurte contra a acne: ele agora vira prescrição".

Percebe-se como no imaginário que se apresenta na publicação 'partes do corpo' são elevadas à categoria de 'entidades personificadas', que têm emoções, se alimentam ou até têm a capacidade de engordar. São as estruturas que devem ser alimentadas. Como observamos na imagem a seguir, na qual há um clamor para que se 'Alimentem os ossos' (dez/2015) e novamente se oferecem o iogurte, pois, segundo a revista, "o iogurte tem um mix de nutrientes que afasta a osteoporose" 4 . Outro aspecto interessante de se notar nesta mesma imagem é um tema que surge das análises aqui empreendidas e que estamos elaborando como "a nutricionalização da família", ou seja, fomenta-se a construção de protocolos alimentares de acordo com estilo de vida por um viés que pressupõe entes familiares. Melhor dizendo, constroem-se tipos ideais de dieta em que certos parâmetros são assumidos como balizadores das fases da vida de cada indivíduo, levando em conta o gênero e os riscos a que se está exposto. O mercado de suplementos alimentares sempre está em jogo, pois de acordo com cada fase é preciso ‘suplementar' partes mais específicas, como os ossos na velhice ou os músculos na juventude.

\section{Considerações finais}

A revista Saúde constrói um discurso que atua em sintonia com o chamado estilo de vida saudável. Pensá-la em sua articulação com uma racionalidade nutricional ${ }^{4}$ é, neste contexto, mais uma ferramenta de abordagem dos modos alimentares e da parte da mídia que se ocupa do alimento. $\mathrm{O}$ fato é que o alimento deixa a fábrica e ganha as prateleiras do mercado literalmente embalado por um discurso midiático da alimentação segura e eficiente. A revista opera no sentido da expansão desta lógica que enquadra e normatiza a comida em sua prática cotidiana, num cenário pós-moderno que favorece a franca expansão e consolidação da racionalidade nutricional ${ }^{4}$, dentro do complexo médico/alimentar industrial. Isto na prática pode ser entendido como a criação de um propósito científico que atualiza alguns conceitos citados anteriormente, tais como, a medicalização da comida e a construção de uma racionalidade nutricional que transformam a comida em passaporte para a saúde perfeita e a longevidade, basta seguir as prescrições.

Tais discursos passam a moldar a produção e distribuição de alimentos e suas estratégias de divulgação, transformando a comida em um bem de consumo que dará sentido ao ser social, reduzindo a comida simbolizada pela cultura a um alimento funcional e medicalizado fornecido pela indústria. Desta forma, a revista opera no sentido da expansão desta lógica que enquadra e normatiza a comida em sua prática cotidiana, naturalizando o consumo e as práticas cotidianas em nome de uma racionalidade que se diz científica, mas não passa de um jogo discursivo de estratégia publicitária. O leitor, os setores da mídia e o setor de produção de alimentos funcionam num registro simbólico hegemônico comum que se coloca como agente normativo das práticas alimentares, respaldado por esse complexo médico/alimentar industrial.

Quando lançamos o olhar para o discurso veiculado por uma mídia, o que se põe em questão é a produção de sentidos no cotidiano. A mídia, com a sua publicidade onipresente não cessa de colonizar o cotidiano das pessoas, bem como as práticas alimentares que são parte desse cotidiano. Há, portanto, uma interação continuada das práticas discursivas com as práticas alimentares e corporais. É importante que se diga que 
a mídia destinada à alimentação não se limita ao universo das revistas, jornais ou sites que tratam do assunto, mas se encontra também e primordialmente impressa nos produtos de gênero alimentício que, por sua vez, estão cada vez mais recobertos de informação. O que é dito sobre os alimentos em suas embalagens, de tão rebuscado e técnico, quase pode ser descrito pelo dispositivo 'Vide bula', tal qual se faz presente nos fármacos.

O consumo de comida, entendida aqui como alimento simbolizado, permite então observar como os indivíduos incorporaram os modelos culturais, os códigos, os estilos de vida, as disposições sociais de seu grupo de pertencimento. Mas o que nos interessa assinalar nesse momento é que a estética, junto com a racionalidade médica e seus modelos (normalidade/patologia ou vitalidade/energia), torna-se o critério sociocultural de enquadramento dos sujeitos para determinar se realmente são 'saudáveis', ou se precisam exercer alguma 'atividade de saúde', por intermédio do estabelecimento de padrões rígidos de forma física. O controle da alimentação é tomado como mandamento da saúde e estar vinculado à 'boa forma' torna-se tão importante quanto vincular-se ao modelo doença/prevenção/cura. Não se trata apenas da medicalização do alimento e da incorporação da racionalidade médica ao consumo de alimentos, pois temos que levar em conta também a funcionalidade do alimento e a forma como atua na construção do corpo ideal.

Na presente reflexão, buscamos analisar o discurso em jogo na produção de sentidos sobre a comida, presentes nos textos da revista Saúde. A revista atua como um meio de divulgação e população de pesquisas do setor de produção alimentícia e farmacológica, mas sempre em sintonia com os interesses desses mercados. Podemos perceber que, na revista, se traduz por saber um pseudo-saber científico que vai informar qual suplemento ou qual prática alimentar é mais indicado para o seu problema de saúde. Reforçando a ideia mecanicista de que para cada doença há uma cura, basta consumir determinado alimento, reforçando também o biologicismo, o reducionismo e o individualismo, porque cada um é responsável pelo que come e basta seguir os preceitos da revista para obter uma saúde perfeita.

Um aspecto da revista que é primordial para o mercado, e para a análise, é o que diz respeito aos aspectos ligados a farmacologização. O material oriundo do marketing farmacêutico presente na revista é farto e merece uma atenção especial. Sua ligação com a comida nesse contexto é muito forte e fundamental para o entendimento das dinâmicas de poder dentro do complexo médico/alimentar industrial, aponta para o investimento na articulação entre medicalização e a indústria do conhecimento. Tal fato tem por efeito a produção de subjetividades em torno do ideal alimentar que desdobram imperativos sobre a comida e objetivações sobre o corpo. O sentido atribuído ao que se come está, cada vez mais, amparado por um ideal de saúde perfeita, onde o perfeito é ter um corpo magro, sobretudo. Os benefícios dos alimentos consumidos são medidos em função dos últimos achados das pesquisas médico-nutricional-farmacêuticas. Num contexto onde se confundem a ética das profissões do campo da saúde com a ética do mercado, percebemos então uma tendência à banalização da evidência científica em função de sua transformação em evidência jornalística.

Trata-se de um jogo em que todos os atores parecem defender os interesses da indústria farmacêutica. Esta, por sua vez, se coloca como a expert para assuntos ligados à suplementação alimentar, reforçando o que talvez seja o nicho mais promissor do mercado farmacêutico global, justamente por contar com uma área de expansão praticamente ilimitada. É justamente essa expansão possivelmente infinita e plástica das normatizações alimentares que justificam o consumo de dispositivos de saúde, dispositivos disciplinares disfarçados de orientações alimentares.

Há uma produção de subjetividade inerente à prática discursiva. Sujeitos se constituem através do discurso. No caso específico do objeto em questão, podemos criar um esquema para sintetizar a noção de práticas alimentares, de modo a incluir o conceito de práticas discursivas. Enquanto o corpo se constitui, do ponto de vista orgânico, por meio da comida, incorporando o alimento, o sujeito se constitui por 
intermédio do discurso, incorporando signos, adotando práticas, estabelecendo sentidos, respaldando-se em significados construídos em mediação com a história.

A comida no imaginário da mídia analisada assume o papel ambíguo, de se configurar como a danação que traz à tona uma série de riscos e, possivelmente, ao mesmo tempo, como a salvação de todos os males, a comida é revestida por uma aura divinizada à qual se atribuem a propriedade da cura, e da 'blindagem da saúde'. Mas a característica mais marcante encontrada nas matérias de capa da revista e, talvez, a característica mais danosa para o consumidor, é o uso instrumental e superficial da comida e sua submissão a uma racionalidade nutricional que medicaliza a vida e transforma qualquer alimento em elixir para todos os males; afinal, basta comer " 5 vegetais por dia - Essa porção reduz em $25 \%$ a chance de você ter qualquer doença" (out/2014) ${ }^{4}$. Temos aqui um exemplo claro de banalização e vulgarização da ciência via um discurso que se diz científico.

\section{Referências}

1. Mira MC. O leitor e a banca de revistas: a segmentação da cultura no séc. XX. São Paulo: Olho d'Água; 2001.

2. Camargo Jr. KR. Medicalização, farmacologização e imperialismo sanitário. Cad. Saúde Pública. 2013 Maio [citado 23 out 2019];29(5):844-46. Disponível em: http://www.scielo.br/scielo.php?script=sci arttext\&pid=S0102-311X2013000500002\&lng=en. doi: 10.1590/S0102-311X2013000500002.

3. Viana MR, Neves AS, Camargo Jr KR, Prado SD, Mendonça ALO. A racionalidade nutricional e sua influência na medicalização da comida no Brasil. Ciênc. saúde coletiva [Internet]. 2017 fev [citado 2019 out 23];22(2):447-456. Disponível em: http://www.scielo.br/scielo.php?script=sci arttext\&pid=S141381232017000200447\&lng=en. doi: http://dx.doi.org/10.1590/1413-81232017222.25432015.

4. Saúde. Página institucional da revista Saúde [Internet]. São Paulo: Abril Mídia SA [Atualizado 2020 mar 16, citado 2015 mar 10]. Disponível em: https://saude.abril.com.br/.

5. Sfez L. A saúde perfeita: critica de uma nova utopia. São Paulo: Edições Loyola, 1996.

6. Spink MJP, Pereira AB, Burin LB, Silva MA, Diodato PR. Usos do glossário do risco em revistas: contrastando "tempo" e "públicos". Psicologia: Reflexão e Crítica. 2008 [citado 2019 out 23];21(1):1-10. Disponível em: http://www.scielo.br/scielo.php?script=sci arttext\&pid=S0102-79722008000100001\&lng $=$ en\&nrm=iso. doi: 10.1590/S0102-79722008000100001.

7. Foucault M. A ordem do discurso: aula inaugural no Collège de France, pronunciada em 2 de dezembro de 1970. 15. ed. São Paulo: Loyola, 2007.

8. Salem T. Manuais modernos de autoajuda: uma análise antropológica sobre a noção de pessoa e suas perturbações. Rio de Janeiro: Uerj; 1992. (Série Estudos Saúde Coletiva; n. 7).

9. Bosi MLM, Prado SD. Alimentação e nutrição em saúde coletiva: constituição, contornos e estatuto científico. Ciênc. saúde coletiva [Internet]. 2011 Jan [citado 23 out 2019];16(1):7-17. Disponível em: http://www.scielo.br/scielo.php?script=sci arttext\&pid=S1413-81232011000100002\&lng=en. doi: 10.1590/S1413-81232011000100002.

10. Kuwae CA, Carvalho MCVS. Ferreira FR, Seixas CM. Mercado do saudável: consumo, alimentação e saúde. In: Prado SD, Kraemer FB, Seixas CM, Freitas RF, organizadores. Alimentação e consumo de tecnologias. v. 1. Curitiba: CRV; 2015. p. 349-62.

11. Carvalho MCVS, Luz MT Prado SD. Comer, alimentar e nutrir: categorias analíticas instrumentais no campo da pesquisa científica. Ciênc. saúde coletiva [Internet]. 2011 Jan [citado 2019 out 23];16(1):155-63. Disponível em: http://www.scielo.br/scielo.php?script=sci arttext\&pid=S141381232011000100019\&Ing=en. doi: 10.1590/S1413-81232011000100019.

12. Simmel G. Sociologia da refeição. Estudos Históricos [Internet]. 2004 jan-jun [citado 2019 out 23];1(33):159-66. Disponível em: http://bibliotecadigital.fgv.br/ojs/index.php/reh/article/ view/2218/1357

13. Miguelote VRS, Camargo Jr KR. Indústria do conhecimento: uma poderosa engrenagem. Rev. Saúde Pública [Internet]. 2010 fev [citado 2019 out 23];44(1):190-96. Available from: http://www.scielo.br/ 
scielo.php?script=sci arttext\&pid=S0034-89102010000100021\&lng=en. doi: http://dx.doi.org/10.1590/ $\underline{\text { S0034-89102010000100021 }}$

14. Cordeiro H. A indústria de saúde no Brasil. Rio de Janeiro: Graal; 1980.

15. Gadelha CAG. O complexo industrial da saúde e a necessidade de um enfoque dinâmico na economia da saúde. Ciênc. saúde coletiva [Internet]. 2003 [citado 23 out 2019];8(2):521-35. Disponível em: http://www.scielo.br/scielo.php?script=sci arttext\&pid=S1413-81232003000200015. doi: http://dx.doi. org/10.1590/S1413-81232003000200015

16. Camargo Jr. KR. Uma biomedicina. Physis [Internet]. 2005 [citado 23 out 2019];15(Supl):177-

201. Disponível em: http://www.scielo.br/scielo.php?script=sci arttext\&pid=S0103-

73312005000300009\&lng=en. doi: 10.1590/S0103-73312005000300009.

17. Conrad P. The Medicalization of society: on the transformation of human conditions into treatable disorders. Baltimore: The Johns Hopkins University Press; 2007.

18. Williams SJ, Martin P, Gabe J. The pharmaceuticalisation of society? A framework for analysis. Sociol Health Illn [Internet]. 2011 [cited 2019 Oct 23];33(7):10-25. Available from: https://onlinelibrary.wiley. com/doi/full/10.1111/j.1467-9566.2011.01320.x. doi: 10.1111/j.1467-9566.2011.01320.x.

19. Castiel LD. Correndo o risco: uma introdução aos riscos em saúde. Rio de Janeiro: Editora Fiocruz; 2010. 